\title{
Management and Efficacy of Intensified Insulin Therapy - Starting in Outpatients
}

\author{
G. Ollenschläger, W. Hummerich, M. Steffen, M. Reincke, B. Allolio, and W. Winkelmann \\ Diabetes Ambulanz der Medizinischen Universitätsklinik II, Köln
}

\begin{abstract}
Summary. Diabetic patients under multiple injection insulin therapy (i.e., intensified insulin therapy, IIT) usually start this treatment during hospitalization. We report here on the logistics, efficacy, and safety of IIT, started in outpatients. Over 8 months, 52 type I and type II diabetics were followed up whose insulin regimens consecutively had been changed from conventional therapy to IIT. Two different IIT strategies were compared: free mixtures of regular and intermediate (12 hrs)-acting insulin versus the basal and prandial insulin treatment with preprandial injections of regular insulin, and ultralente ( $24 \mathrm{hrs}$-acting) or intermediate insulin for the basal demand. After 8 months HbA1 levels had decreased from $10.6 \% \pm 2.4 \%$ to $8.0 \% \pm 1.3 \%$ (means $\pm S D$ ). There was no difference between the two regimens with respect to metabolic control; but type II patients maintained the lowered HbA1 levels better than type I patients. Only two patients were hospitalized during the follow-up time because of severe hypoglycemia. An increase of body weight due to the diet liberalization during IIT became a problem in one-third of the patients. Our results suggest that outpatient initiation of IIT is safe and efficacious with respect to near-normoglycemic control. Weight control may become a problem in IIT patients.
\end{abstract}

Key words: Intensified insulin therapy - Outpatient treatment - Diabetes mellitus

In recent years, new approaches in the treatment of insulin-dependent diabetes mellitus (IDDM) have been developed in order to achieve near-normoglycemia. New devices for insulin injections (e.g., insulin pens) [2] can be used, which might

Abbreviations: $B P I T=$ basal and prandial insulin therapy; FMIT $=$ free mixture insulin therapy; IIT $=$ intensified insulin therapy enhance patients' motivation to prefer multiple injection therapy (i.e., the intensified insulin therapy) to conventional regimens [11].

Insulin regimens are usually initiated or changed during hospitalization, in order to control strictly the metabolic instabilities of the initiation period [10]. Nevertheless, there are some arguments in favor of changing insulin therapy on an outpatient basis: insulin requirements are adapted much faster to the patient's usual way of life, especially with regard to physical activities, and to the normal diet. Furthermore, the costs of an outpatient treatment are much lower compared with hospitalization.

The aim of our study was to evaluate the management and efficacy of an outpatient initiation of intensified insulin therapy (IIT), with respect to metabolic control, as well as patients' compliance, and therapeutic safety. We were also interested in comparing the two different strategies of IIT, namely the use of free mixtures of regular and intermediate-acting insulin (FMIT) versus the multiple insulin injection therapy, which has been called "basal and prandial insulin therapy" (BPIT) [7].

\section{Patients and Methods}

\section{Subjects, Insulin Therapy}

We studied 23 type I and 29 type II diabetics who consecutively started intensified conventional insulin therapy as outpatients between January and December 1986. The comparison between the two types of treatment (FMIT, BPIT) was based on randomized allocation.

Types of Intensified Insulin Therapy

FMIT Group (Free Mixture Insulin Therapy). Patients mixed their combinations of regular and intermediate-acting insulin in the syringe, according 
to the individual demand, immediately before the morning and evening injections. Insulin doses were chosen according to the algorithms of Holman and coworkers [7] and Schiffrin [14], and were modified in correspondence to carbohydrate intake and expected physical activities. If necessary, additional regular insulin was injected at dinner or during hyperglycemic phases. Some patients had to divide their evening injections into preprandial regular and bedtime intermediate insulin applications. For FMIT only NPH insulin was used as the intermediate-acting insulin because of the reproducible bioavailability of regular insulin from these mixtures [1].

BPIT Group (Basal and Prandial Insulin Therapy). Prandial insulin was injected with fountain-pen like syringes, containing $100 \mathrm{U}$ regular insulin (Novopen, Novo), usually thrice a day. The basal insulin requirements were covered with a 24 -h-acting suspension of human crystalline zinc insulin (U1tratard HM, Novo). This long-acting insulin was changed to intermediate-acting insulin if necessary. Basal insulin was injected into the abdominal subcutaneous fat at 10 p.m.

The patients were followed up prospectively for at least 8 months.

The clinical data and the insulin regimens of the patients are listed in Table 1. Body weight prior to the study period was normal $(90 \%-110 \%$ ideal body weight [13]) in $62 \%$ of the type I group and $44 \%$ of type II. Overweight was noted in $17 \%$ of type I and $56 \%$ of type II patients, and underweighted in $21 \%$ of type 1 .

\section{Inclusion and Exclusion Criteria}

The study followed the principles of the Declaration of Helsinki and each patient gave his informed

Table 1. Data of the intensive insulin treatment (IIT) outpatients

\begin{tabular}{lllll}
\hline $\begin{array}{l}\text { Diabetes } \\
\text { type }\end{array}$ & $\begin{array}{l}\text { Insulin } \\
\text { therapy }\end{array}$ & $n$ & $\begin{array}{l}\text { Age } \\
\text { (years/mean } \\
\pm \text { SD) }\end{array}$ & $\begin{array}{l}\text { Duration } \\
\text { of diabetes } \\
\text { (years) }\end{array}$ \\
\hline I & FMIT + & & & \\
& BPIT & 23 & $25.6 \pm 6.6$ & $11.9 \pm 8.9$ \\
I & FMIT & 12 & $23.6 \pm 5.5$ & $9.4 \pm 8.7$ \\
I & BPIT & 11 & $27.5 \pm 7.7$ & $12.6 \pm 9.0$ \\
II & FMIT + & & & \\
& BPIT & 29 & $50.7 \pm 11.2$ & $8.0 \pm 7.1$ \\
II & FMIT & 18 & $51.7 \pm 11.2$ & $8.2 \pm 6.5$ \\
II & BPIT & 11 & $49.7 \pm 10.9$ & $7.7 \pm 7.7$ \\
\hline
\end{tabular}

FMIT, free mixture insulin therapy; BPIT, basal and prandial insulin therapy consent. Before the study, all patients had been treated by conventional insulin therapy, i.e., one or two daily injections of fixed (industrially premixed) mixtures, containing $20 \%-30 \%$ regular insulin together with intermediate insulin. All patients had been referred to our outpatient clinic by other departments of the university hospital or by their family doctors because of insufficient metabolic control.

Only those diabetics were included in the study who had been familiar with conventional insulin therapy for at least 6 months. Study patients had to monitor and document their blood-glucose levels regularly; furthermore, they had to pass a 1-week ambulatory education program (Table 2). Every 4 weeks a visit to the diabetes clinic was obligatory during the follow-up time. Diabetics who live alone were excluded from the study, as were those without a telephone connection. Further exclusion criteria included gravidity and impaired sensation of hypoglycemic symptoms.

\section{Management of Outpatient Initiation of IIT}

\section{Self-Monitoring Procedures}

One week before IIT started, a member of the diabetes team instructed the patient in how to handle self-monitoring of blood glucose with color sticks (Hämoglucotest 20-800, Boehringer Mannheim). Acetonuria and glucosuria had to be monitored, whenever the patient suffered from polydipsia and polyuria, as well as during episodes of fever and/or when blood glucose rose to levels of more than $250 \mathrm{mg} / \mathrm{dl}$. Whenever patients came to see the diabetes team, capillary blood-glucose levels were tested simultaneously by the patient, the nurse, and the hospital laboratory, to compare the results of colour sticks, reflectant meter (Reflocheck, Boehringer Mannheim), and a standardized glucose oxidase method. Discrepancies of less than $20 \%$ between the laboratory's and patient's results were accepted as accurate self-monitoring. During the first 3 to 4 weeks of IIT, blood-glucose monitoring was made at least 7 times a day, i.e., before and after breakfast, dinner, lunch, and at bedtime. During the first week, the patients also tested between 3 and 4 a.m.

With respect to hypoglycemia, patients were instructed to consume adequate doses and types of carbohydrates. The patients' family partners had been informed about the correct use of glucagon injections in case of hypoglycemia with unconsciousness. 
Table 2. Curriculum of the educational program for IIT outpatients

\begin{tabular}{llllll}
\hline Time & Monday & Tuesday & Wednesday & Thursday & Friday \\
\hline $\mathbf{1 0}$ a.m. & Introduction: & Diet: & Late complications & Diet: & Diet: \\
$\mathbf{- 1 2}$ a.m. & problems of & Carbohydrate & Hygiene & Composition & Calculation of \\
& the diabetics & exchange & Drug therapy & of meals & energy intake \\
& & Glycemic index & Sports and exercise & outside home & The individual \\
& of foods & & Alcohol and & diet plan \\
& Problems with & & diabetes & Meals during \\
& diet liberalization & & & travel and illness \\
& & & & & \\
& & & & &
\end{tabular}

$\begin{array}{ll}\text { 12 a.m.- } & \text { Individual metabolic } \\ \text { 13.30 p.m. } & \text { self-monitoring and lunch with the dietician }\end{array}$

\begin{tabular}{llllll}
\hline 13.30 p.m.- & Diet: & Technique of & Dietetic products: & Diet: & Social problems: \\
15 p.m. & Basics on nutrients & Insulin handling & Ingredients & Technique of & Professions \\
& Calculation and & Injection & Estimation of & cooking & for diabetics \\
& estimation of & Self-monitoring & carbohydrates, & Estimation of & Family \\
carbohydrates & & protein, fat & nutrients & Genetics \\
& & & Buffet dinner & \\
\hline
\end{tabular}

\begin{tabular}{lcccc}
\hline $\begin{array}{l}15 \text { p.m.- } \\
15.30 \text { p.m. }\end{array}$ & $\begin{array}{l}\text { Individual metabolic } \\
\text { self-monitoring and break with the dietician }\end{array}$ & \\
\hline 15.30 p.m.- & $\begin{array}{c}\text { Metabolism: } \\
\text { Basics and } \\
\text { imbalances }\end{array}$ & $\begin{array}{l}\text { Insulin: } \\
\text { Types and action } \\
\text { Algorithms for } \\
\text { hypo- and } \\
\text { hyperglycemia }\end{array}$ & $\begin{array}{c}\text { Insulin adaption: } \\
\text { Algorithms for } \\
\text { hypo- and } \\
\text { hyperglycemia }\end{array}$ & $\begin{array}{c}\text { Insulin adaption: } \\
\text { Changing the diet; } \\
\text { in case of } \\
\text { illness, } \\
\text { sports, travel }\end{array}$ \\
\hline
\end{tabular}

\section{The First Weeks of Outpatient IIT}

One week before changing the insulin regimen, patients began to monitor blood glucose. The diabetics had to observe strictly a standardized diet until a stable metabolic control was reached. FMIT patients mixed regular and intermediate insulin by themselves in the habitual proportions. At the beginning of the 2nd week, the FMIT patients were instructed in how to modify insulin dosages, according to the self-monitored data.

BPIT patients injected for the last time the fixed mixture on the morning of the new regimen's 1 st day. Ultratard HM was injected at 10 p.m. During the first months about $50 \%$ to $60 \%$ of the daily insulin amount was applied in the form of longacting insulin, following the algorithms of Holman [7]. Subsequently, the doses of basal insulin were lowered in favor of the amount of regular insulin. The increase of the Ultratard dosage was not allowed earlier than every 4 th to 5 th day because of the saturation characteristics of this drug [16]. An adequate Ultratard dose is characterized by near-identical blood-glucose levels at bedtime, at night, and in the morning. If a patient did not reach this stabilization, the long-acting insulin was replaced by intermediate-acting insulin injected at bedtime as well.
During the 1st week of the new treatment, the patient came to see the diabetologist every day to discuss the insulin-dosage adaptation. After that, a weekly visit was obligatory, until a stable metabolic control was reached. In cases of unexpected or inexplicable hypo- and hyperglycemia, a 24-h telephone service was made available to the patients. After metabolic stabilization insulin therapy and HbA1 levels were controlled monthly and a liberalization of the diet was allowed: instead of fixed times and amounts of carbohydrate intake free choice of meal times and free distribution of energy substrates over the day were permitted.

\section{Follow-Up Parameters}

The daily amount of total insulin as well as the fraction of long-(intermediate-)acting insulin, the daily injection frequency, the frequency of hypoglycemias (slight hypoglycemias were defined as blood glucose levels below $50 \mathrm{mg} / \mathrm{dl}$ ), and the course of body weight were determined.

A standardized glucose oxidase method was used for blood-glucose determination. For the HbA1 determination an ion exchange chromatography method (HbA1 Assay, Panchem) was used; the normal range in our laboratory was $5.5 \%-8.5 \%$ of total hemoglobin. 


\section{Statistics}

Significances of the mean differences of the two groups (FMIT vs BPIT) were calculated using Student's $t$-test for unpaired data. The intraindividual differences were compared using Student's $t$-test for paired data. For analysis of variance, the Hartley test was used [14].

\section{Results}

Details of the follow-up evaluation are shown in Tables 3 and 4. All patients of the FMIT group used the regimen to which they had been switched, for the entire study time. Six of the BPIT patients had to change their basal insulin regimen due to repeated hypoglycemias. Three patients continued with NPH insulin at bedtime (two type II, one type I), three patients (all of them type II) injected only regular insulin. All BPIT patients injected three to four times a day, in contrast to only eight of the 30 FMIT patients.

\section{Frequency of Side Effects}

During the study period, the frequency of slight hypoglycemias per month in diabetic patients of type I on FMIT was $9.5 \pm 5.6$ and on BPIT it was $10.8 \pm 4.9$; type II patients on FMIT had $9.9 \pm 5.7$ and those on BPIT had $11.2 \pm 5.2$ episodes per month. As only eight of the patients had protocolled irregularly hypoglycemic events and glucose levels before entering the study, we were not able to evaluate the slight hypoglycemias of the preceding time for the whole group. For the eight patients, the prestudy frequency of slight hypoglycemias was $4.9 \pm 3.3$ per month.

Severe hypoglycemia was defined as an episode in which the patient was not able to take carbohydrates himself, but needed the assistance of another person. This occurred in one FMIT and one BPIT patient, who had to be hospitalized for treatment of hypoglycemia with unconsciousness. The FMIT patient mistook the evening dose of intermediate insulin as regular insulin. The other one suffered from primary hyperparathyreoidism; after surgery, severe hypoglycemia did not recur. The year before entering the study, four of the patients had suffered from severe hypoglycemias with a total of five episodes.

We did not observe any ketoacidosis or hyperosmolar nonketotic coma during the study period.

\section{Courses of $H b A 1$}

After 2 months of intensified insulin therapy, all type II diabetics and 21 of 23 type I diabetics had significantly decreased $\mathrm{HbA} 1$ levels compared with at the beginning of the study (in type II this was $66 \%$ and in type $I 72 \%$ of the initial values), inde-

Table 3. HbA1 before and during IIT (means + SD)

\begin{tabular}{|c|c|c|c|c|c|}
\hline $\begin{array}{l}\text { Diabetes } \\
\text { type } \\
\text { Therapy }\end{array}$ & & $\begin{array}{l}\text { HbA1 } \\
\text { before IIT } \\
(\% \mathrm{Hb})\end{array}$ & $\begin{array}{l}\text { Before vs } 2 \\
\text { and } 8 \text { months } \\
(P)\end{array}$ & $\begin{array}{l}\mathrm{HbA} 1 \\
\text { after } 2 \text { months } \\
\text { IIT } \\
(\% \mathrm{Hb})\end{array}$ & $\begin{array}{l}\text { HbA1 } \\
\text { after } 8 \text { months } \\
\text { IIT } \\
(\% \mathrm{Hb})\end{array}$ \\
\hline I & $\begin{array}{l}\text { FMIT } \\
\text { BPIT }\end{array}$ & $\begin{array}{r}10.8 \pm 2.3 \\
9.7 \pm 2.2\end{array}$ & $\begin{array}{l}<0.005 \\
<0.005\end{array}$ & $\begin{array}{l}7.4 \pm 1.1 \\
7.3 \pm 1.2\end{array}$ & $\begin{array}{l}8.1 \pm 1.4 \\
8.6 \pm 1.6 *\end{array}$ \\
\hline $\begin{array}{l}\text { II } \\
\text { II }\end{array}$ & $\begin{array}{l}\text { FMIT } \\
\text { BPIT }\end{array}$ & $\begin{array}{l}10.8 \pm 2.0 \\
10.5 \pm 2.0\end{array}$ & $\begin{array}{l}<0.005 \\
<0.005\end{array}$ & $\begin{array}{l}7.6 \pm 1.1 \\
7.2 \pm 1.0\end{array}$ & $\begin{array}{l}7.9 \pm 1.1 \\
7.9 \pm 1.2\end{array}$ \\
\hline
\end{tabular}

$* p<0.05$

Table 4. Daily need of insulin before and during IIT (means + SD)

\begin{tabular}{|c|c|c|c|c|c|c|}
\hline \multirow{2}{*}{$\begin{array}{l}\text { Diabetes } \\
\text { type } \\
\text { Therapy }\end{array}$} & & \multicolumn{2}{|c|}{$\begin{array}{l}\text { Daily amount of insulin } \\
(\mathrm{U} / \mathrm{kg} \mathrm{BW})\end{array}$} & \multicolumn{3}{|c|}{$\begin{array}{l}\text { Basal insulin } \\
\text { ( } \% \text { of total daily insulin amount) }\end{array}$} \\
\hline & & Before IIT & After 4 months* & Before IIT & After 4 months* & After 8 months* \\
\hline I & FMIT & $0.72 \pm 0.3$ & $0.52 \pm 0.2$ & $76.8 \pm 13.2$ & $69.3 \pm 13.7$ & $60.1 \pm 14.1$ \\
\hline$I$ & BPIT & $0.75 \pm 0.2$ & $0.51 \pm 0.2$ & $78.0 \pm 14.4$ & $56.6 \pm 12.2$ & $42.3 \pm 8.4$ \\
\hline II & FMIT & $0.65 \pm 0.3$ & $0.52 \pm 0.2$ & $79.0 \pm 16.6$ & $69.9 \pm 19.3$ & $63.2 \pm 17.8$ \\
\hline II & BPIT & $0.78 \pm 0.4$ & $0.56 \pm 0.3$ & $74.0 \pm 18.0$ & $57.1 \pm 15.9$ & $42.1 \pm 10.8$ \\
\hline
\end{tabular}

* $P<0.0001$ vs before IIT 
pendently of the type of IIT (Table 3). All type II patients were able to keep this glycemic control throughout the study time. Four type I had elevated $\mathrm{HbA1}$ levels after 8 months, compared with the initial values (median 107\%, range $102 \%-118 \%$ of initial values).

\section{Daily Demand of Long- and Intermediate-Acting Insulin}

The intermediate-(long)-acting insulin amount, which was comparable in all patients before IIT (about $77 \%$ of the total daily insulin amount), decreased more with BPIT (to $57 \%$ after 4 months and $42 \%$ after 8 months; means of $n=16$ ) than with FMIT $(70 \%$ after 4 and $62 \%$ after 8 months; Table 4).

\section{Courses of Body Weight}

Only three of the type II patients were able to reduce their body weight during IIT (to a median of $95 \%$, range $87 \%-99 \%$, of their original body weight), and six of the type I patients (to $93 \%$, range $89 \%-97 \%$ ). Seven of the type I diabetics and 12 of the type II patients gained body weight (to $105 \%$, range $101 \%-107 \%$ of original body weight in type $I$, and $107 \%$, range $103 \%-110 \%$, of original body weight in type II). The weight changes did not correlate with the courses of HbA1, insulin need, or type of treatment.

\section{Discussion}

This is the first follow-up study to show that the change of an insulin regimen from conventional to intensified therapy is possible and safe in outpatients. There are eight studies in the literature which describe the initiation of insulin therapy in newly diagnosed insulin-dependent outpatients (for references see [19]). The most striking difference in results between those studies and ours is the level of glycemic control achieved.

Wilson et al. [19] as well as Whitehouse et al. [18] mention $\mathrm{HbA} 1$ levels above $10 \%$ after 12 , respectively 6 months of treatment. It was our intention to correct the metabolic situation to near-normoglycemic levels in our patients. With the exception of four type I diabetics, all persons fullfilled this criterion with mean $\mathrm{HbA} 1$ levels of about $8 \%$. This is in accordance with other studies on the therapeutic effect of IIT [5, 17]; none of these results had been obtained after initiation in outpatients.

The most relevant acute problem of IIT is the danger of severe, life-threatening hypoglycemia [17]. To avoid severe metabolic derangements, especially during the initiation phase, very strict criteria had to be fullfilled for the patients to enter the study. In addition, to get the outpatients accustomed to the new treatment, we changed the habitual proportions of basal and regular insulin very slowly (see Table 4).

The frequency of slight hypoglycemic periods usually increases as a consequence of the IIT-induced near-normoglycemia [9]. This was also the fact in eight of the investigated patients. Nevertheless, the incidence of severe hypoglycemias decreased in this group; possibly because of the patients' regular self-monitoring.

Nearly all patients succeeded in controlling blood-glucose levels much better with intensified than with conventional insulin therapy. It may be criticized that our study is lacking a control group on conventional therapy. A lot of studies have been published showing the superiority of IIT over conventional methods $[12,17]$. Therefore, it was also the aim of our investigation to compare different methods of intensified conventional insulin treatment. There is no advantage of the one intensified regimen compared with the other with respect to the HbA1 levels. The efficacy of IIT depends much more on the diabetes type and the individual background of the patient. The higher portion of basal insulin in the FMIT group than in the BPIT group has no influence on the incidence of hypoglycemia, the course of weight, and the HbA1 levels. It is our observation that the main factor for improved metabolic control is not the type of IIT, but the patient's ability to handle blood glucose self-monitoring and to modify the dosages of regular insulin [8].

On the basis of our results we submit that IIT is to be recommended not only for type $\mathrm{I}$, but also for those insulin-dependent type II patients in whom near-normoglycemia is necessary. We used IIT in teachable type II diabetics with a longer life expectancy (the mean age of the type II study group is 50 years). The adequate control of body weight after the change from a strict diet to variations of food intake, which BPIT makes possible, seems to be one of the central problems of IIT. One-third of our IIT diabetics experienced an undesirable increase of body weight, which is in accordance with the results of Capper et al. [3] and of other groups [17], but in contrast to those of Chantelau et al. [4]. As a consequence of our results, we changed our educational program with respect to dietetics. We now focus on nutrient exchange and variation of meal times much more 
than on food liberalization, as we did before. In spite of the increased food intake of several patients, the mean daily total insulin amount is much lower during IIT compared with the conventional regimens. Therefore, we presume that the weight gain is primarily due to a higher intake of noncarbohydrate calories, as has been described for diabetics during pump therapy [3].

The reduced daily total insulin amount is a result of the decreased dosages of intermediate- and long-acting insulin, as well as of the accurate insulin adaptation to physical activity.

In some patients, the kinetics of the long-acting insulin are not adequate to the increased insulin need during the early-morning phase [16]. In these patients, a late bedtime application of intermediate-acting insulin was able to overcome the blood glucose rise in the morning. Otherwise insulin pumps, with various basal rates, may be considered.

Some type II diabetics needed very little amounts of basal insulin during IIT, and could be controlled only by regular insulin. Therefore, every type II patient should be tested to determine whether a basal activity of the endocrine pancreas remains. In such cases, preprandial regular insulin alone is a very convenient mode of insulin treatment, especially if an insulin pen is used $[6,9]$.

In conclusion, we were able to demonstrate a safe and, with regard to the metabolic control and acceptance, efficient way of starting intensified insulin therapy in outpatients. The two discussed concepts of IIT are comparable with respect to safety and effectivity. The daily basal insulin need is much lower with the prandial basal insulin regimen compared with the free mixture insulin therapy, which may be advantageous, especially in hyperinsulinemic diabetics.

Acknowledgments. We gratefully acknowledge the cooperation of our diabetes team, namely E. Beiersmann RD, H. Golling RN, H. Moll RD, and K. Neumaier RD.

\section{References}

1. Berger $M$, Cüppers HJ, Hegner $H$, Jörgens V, Berchtold $P$ (1982) Absorption kinetics and biological effects of subcutaneously injected insulin preparations. Diabetes Care 5:77-91

2. Berger AS, Saurbrey N, Kühl C, Villumsen J (1985) Clinical experience with a new device that will simplify insulin injections. Diabetes Care 8:73-76

3. Capper FA, Headen SW, Bergenstal RM (1985) Dietary practices of persons with diabetes during insulin pump therapy. J Am Diet Assoc 85:445-449

4. Chantelau EA, Frenzen A, Gösseringer G, Hansen I, Berger $M$ (1987) Intensive insulin therapy justifies simplification of the diabetes diet: a prospective study in insulin-dependent diabetic patients. Am J Clin Nutr 45:958-996

5. Hanssen KF, Dahl-Joergensen K, Lauritzen T, Feldt-Rasmussen B, Brinchmann-Hansen O, Deckert T (1986) Diabetic control and microvascular complications: the nearnormoglycaemic experience. Diabetologia 29:677-684

6. Heinze P, Stahl A, Glasmacher A, Ahlert U (1988) Intensiviertes Insulintherapieregime: Tags multiple Injektionen eines kurzwirkenden Insulins, nachts Verzögerungsinsulin als "Bedside-Dosis". Akt Endokr Stoffw 9:112

7. Holman RR, Turner RC (1985) A practical guide to basal and prandial insulin therapy. Diabet Med 2:45-53

8. Jörgens V, Berger M, Hornke L (1982) Die Bedeutung der Patientenschulung in der Behandlung des Diabetes mellitus. Deutsch Ärzteblatt 79:47-50

9. Krönke HJ, Sieber J, Reuber E, Lütke-Twenhöven A, Rathmann W, Bertrams J (1987) Langzeitergebnisse bei 45 Diabetikern mit dem Basis-Bolus-Insulin-Regime. Akt Endokr Stoffw 8:206

10. Marble A (1985) Insulin in the treatment of diabetes. In: Marble A, Krall CP, Bradley RF, Christlieb AR, Soeldner JS (eds) Joslin's Diabetes mellitus, 12th edn. Lea and Febinger, Philadelphia, pp 380-405

11. Rizza RA, Gerich JE, Haymond MW, et al. (1980) Control of blood sugar in insulin-dependent diabetes: comparison of an artificial endocrine pancreas, continuous subcutaneous insulin infusion, and intensified conventional insulin therapy. N Eng1 J Med 303:1313-1318

12. Rosak C, Böhm BO, Althoff PH, Schöffling K (1986) The basis-bolus-concept in insulin-therapy: renaissance of an old therapentical regime. Med Klinik $81: 341-345$

13. Roth E, Ollenschläger G, Hackl JM (1985) Grundlagen und Technik der Infusionstherapie und klinischen Ernährung. In: Reissigl H (Hrsg) Handbuch der Infusionstherapie und klinischen Ernährung, Band II. Karger, Basel München, S 38

14. Sachs L (1984) Angewandte Statistik, 6th edn. Springer, Berlin Heidelberg New York

15. Schiffrin A (1982) Treatment of insulin-dependent diabetes with multiple subcutaneous insulin injections. In: Raskin $\mathrm{R}$ (ed) Symposium on diabetes mellitus. Med Clin North Ain 66:1251-1267

16. Spuck W, Schweinebraten A, Thun C, Gerdes H (1987) Intensified insulin therapy: single dose substitution of nonmeal-related (basal) insulin by long acting human zinc insulin. Med Klinik 82:51-55

17. The DCCT Research Group (1987) Diabetes control and complications trial (DCCT): results of a feasibility study. Diabetes Care 10:1-19

18. Whitehouse FW, Whitehouse IJ, Cox MS, et al. (1983) Outpatient regulation of the insulin-requiring person with diabetes (an alternative to hospitalization). J Chron Dis $36: 433-438$

19. Wilson RM, Clarke P, Barkes H, Heller SR, Tattersall RB (1986) Starting insulin treatment as an outpatient. Report of 100 consecutive patients followed up for at least one year. JAMA 256:877-880

Received: July 4, 1988

Returned for revision: October 7, 1988

Accepted: November 3, 1988

Dr. Dr. med. G. Ollenschläger

Medizinische Universitätsklinik II

Joseph-Stelzmann-Str. 9,

D-5000 Köln 41 